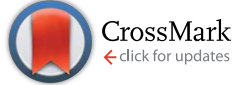

Cite this: RSC Adv., 2015, 5, 43462
Received 1st April 2015

Accepted 29th April 2015

DOI: $10.1039 / c 5 r a 05825 b$

www.rsc.org/advances

\title{
Depression in glass transition temperature of multiwalled carbon nanotubes reinforced polycarbonate composites: effect of functionalization $\uparrow$
}

\begin{abstract}
Arun Singh Babal, Ravi Gupta, Bhanu Pratap Singh* and Sanjay R. Dhakate
Functionalized multiwalled carbon nanotubes (a-MWCNTs) and non-functionalized MWCNTs were melt mixed with polycarbonate polymer by utilizing twin screw micro compounder having a back flow channel to obtain nanocomposites with varying composition from 0.5 to $10 \mathrm{wt} \%$ MWCNT and $2 \mathrm{wt} \%$ a-MWCNT. Mechanical properties of composite samples were studied using dynamic mechanical analyzer, flexural and tensile tests. Both DMA and flexural and tensile tests suggest formation of continuous network of CNT-polymer that is supported by measured storage modulus for different loading of MWCNT and a-MWCNT. The composite sample showed lower glass transition temperature $\left(T_{\mathrm{g}}\right)$ as compared to pure PC. Effect of functionalization of MWCNTs on $T_{\mathrm{g}}$ of its of polycarbonate composites is studied and showed higher $T_{\mathrm{g}}$ depression in functionalized MWCNTs compared to non functionalized MWCNTs based composites over pure polycarbonate. In DMA, lowering of height of tan delta peak indicates that polymer in composite material participating in $T_{\mathrm{g}}$ was reduced along with loading of MWCNT, consistent with immobilization of polymer material present at the CNT interface. Effect of functionalization on morphology was investigated using scanning electron microscope and confirms the better interaction in case of a-MWCNTs compare to MWCNTs based composites. Further, Raman spectroscopic analysis indicates higher interaction between a-MWCNT and PC matrix as compared to as synthesized MWCNT.
\end{abstract}

\section{Introduction}

Ever since the discovery of carbon nanotubes (CNTs) by Iijima, ${ }^{\mathbf{1}}$ most of the research is focused on the area of using CNTs as a filler in plastic industry to overcome the demands of the modern civilization. ${ }^{2}$ CNTs have incredibly high mechanical, electrical ${ }^{3-5}$ and thermal properties ${ }^{6,7}$ with low density. Light-weight materials can be used for advanced technologies like aerospace components, automobiles, adaptive and smart materials as well as for military purposes. Light weight multifunctional polymer nanocomposites with enhanced properties are synthesized by incorporation of CNTs into host material. The final properties of the resulting composite depend on the inherent properties of filler such as filler aspect ratio, size and dimension, three dimension orientation and spacing in filler in the matrix.

Polycarbonate (PC) is an engineering thermoplastic polymer having low molecular weight demonstrates high mechanical strength over a wide range of temperature scale. PC inherent

Physics and Engineering of Carbon, CSIR-National Physical Laboratory, New Delhi, 110012, India. E-mail: bps@nplindia.org; bpsingh2k4@yahoo.com; Fax: +91-1145609310; Tel: +91-11-45608460

$\dagger$ Electronic supplementary information (ESI) available. See DOI: $10.1039 / \mathrm{c} 5 \mathrm{ra} 05825 \mathrm{~b}$ properties like corrosive resistance, high toughness, flame resistance and heat resistance etc. make it suitable candidate for the high performance CNT/PC composite material., ${ }^{5,8-10}$ Although, researchers have fabricated composite samples via using different techniques such as melt mixing, ${ }^{11}$ solution casting $^{12}$ and in situ polymerization; ${ }^{13}$ melt mixing is the most preferred method due to the reason of high industrial viability. Homogeneous dispersion of CNTs in matrix plays a key role in enhancing the properties of composite material. The multiwalled carbon nanotubes (MWCNTs) reinforced polymer nanocomposites shows less increment in mechanical properties than theoretically proposed that related to the various factors importantly nanotube aggregates/agglomeration. ${ }^{\mathbf{1 4 - 1 6}}$ Formation of aggregates leads to less interfacial interaction between MWCNT and polymer, lower available surface area and less stress transfer between matrix polymer and MWCNT. ${ }^{\mathbf{1 4 , 1 7 , 1 8}}$ Melt mixing technique allow uniform dispersion of CNTs, due to the presence of appropriate shear force during mixing.

Viscoelastic properties are taken into consideration in long term structural design and being characterized using dynamic mechanical thermal analysis (DMTA) tool. At this point, we focus only on former literature on the experimental studies reporting the dynamic mechanical properties of composite 
materials. Various studies have been done to analyze the dynamic mechanical properties, but for this topic, there is a lack of agreement among the various researchers. As for the MWCNT/PC composites, there is a limitation on availability of studies on dynamic mechanical properties. Few researchers have reported decline in glass transition temperature $\left(T_{\mathrm{g}}\right)$ with increase in MWCNT loading. Castillo et al. fabricated varying composition of CNT/PC composites using extrusion (DSM twinscrew micro compounder) followed by compression molding. ${ }^{19}$ In this case, DMA test suggest the increment in storage modulus after $T_{\mathrm{g}}$ due to reinforcement effect of CNT as well as polymerCNT continuous network formation. But the composites showed decline in both $\tan \delta$ and $T_{\mathrm{g}}$ value. Sung et al. studied various composition from 1.5-15 wt\% MWCNT fabricated by extrusion followed by compression molding using hot press. ${ }^{20}$ They only reported the effect of annealing on the $T_{\mathrm{g}}$ of composite samples. Wang et al. fabricated composite samples with 2 and 20 wt $\%$ SWCNT loading in PC polymer. ${ }^{21}$ They stated improvement by a factor of 3.4 for $20 \mathrm{wt} \%$ SWCNT/PC composite as compared to the neat PC. Guo et al. reported the effect of aspect ratio of CNTs on composite properties, for concentration of SWCNT loading up to $3 \% .^{22}$ They informed greater depression of $T_{\mathrm{g}}$ and higher increment in storage modulus for CNTs with high aspect ratio as relative to the low aspect ratio CNTs.

Khare et al. studied the effect of CNT dispersion on $T_{\mathrm{g}}$ in cross linked CNT/epoxy composite. ${ }^{23}$ They observed that the composite containing higher dispersion of CNTs shows a greater decline in $T_{\mathrm{g}}$ as compared to the pure epoxy sample. On the other hand, composite with agglomerated CNT with same concentration did not show such a greater decline. Fidelus et al. studied effect of both SWCNT and MWCNT on two type of epoxy polymer (LY 564 and Epon 815). ${ }^{24}$ There was slight decline in $T_{\mathrm{g}}$ in LY 564 epoxy composite for both SWCNT and MWCNT but Epon 815 epoxy composite shows no significant changes. Boncel et al. reported the decrement in $T_{\mathrm{g}}$ when MWCNT reinforced polysterene polymer were studied. ${ }^{25}$ Guadagno et al. studied the $\mathrm{COOH}$ functionalized MWCNT reinforced epoxy composites using DMA and reported a constant value or decrement in storage modulus. ${ }^{26}$ Amr et al. studied the acid functionalized MWCNT reinforced polystyrene composite using DSC and reported that acid functionalized MWCNT act as a plasticizer. ${ }^{27}$

At present, no studies have been previously reported the effect of functionalization on dynamic mechanical properties of composite prepared by melt mixing, comprising justification of outcome resulting from the PC composites. This work is mainly dedicated to study the effect of functionalization of MWCNT with respect to as synthesized MWCNT on the dynamic mechanical properties of PC composites. Highly uniform distribution of MWCNT in matrix is achieved by utilizing the twin screw extrusion (thermo Scientific HAAKE MiniLab) with back flow channel which provide appropriate shear force followed by injection molding. These attempts were made to associate the interfacial characteristic i.e. chain mobility with dynamic thermo mechanical properties of the MWCNT/ polycarbonate composites.

\section{Experimental}

\section{Material}

In this study, PC (Bayer Material Science, MAKROLON® 2407) was used as a matrix. By employing catalytic chemical vapor deposition technique, MWCNT were produced by thermal decomposition of hydrocarbon source (toluene, $\mathrm{C}_{6} \mathrm{H}_{5} \mathrm{CH}_{3}$ ) in a $18 \mathrm{~cm}$ long constant heating zone of quartz tube in the presence of catalyst source (ferrocene, $\mathrm{C}_{10} \mathrm{H}_{10} \mathrm{Fe}$ ) under an inert atmosphere. For further details see elsewhere. ${ }^{28}$ Nitric acid, toluene and ferrocene from sigma were used as received. As produced MWCNT was functionalized by refluxing in nitric acid for $48 \mathrm{~h}$ (ref. 29-31) and designated as a-MWCNT.

\section{Nanocomposite fabrication}

Pre-dried polycarbonate granules $\left(100{ }^{\circ} \mathrm{C}\right.$, overnight $)$ were melt mixed with specific amount of a-MWCNT (2 wt\%) and different amount of MWCNT $(0.5,1,2,5,10 \mathrm{wt} \%)$ by employing HAKKE MiniLab II Micro compounder followed by injection molding to inject the melt into the mold. Previous investigations have showed that high melting temperature along with high rotational speed of screw for mixing can lead to uniform distribution of CNTs. High shear stress applied by the screws can potentially cause rupture of the nanotube fillers. Therefore, melting temperature of $290{ }^{\circ} \mathrm{C}$ and screw rotation speed $100 \mathrm{rpm}$ was preferred. This composite fabrication process was optimized and elaborated in elsewhere. ${ }^{11}$ In this study, mold ASTM 790 (flexural) and mold according to ASTM 638 (dog bone shape) were used to shape the composites melt. In order to study, dynamic mechanical properties of composites specimens were cut into dimension of $12.5 \mathrm{~mm} \times 6.3 \mathrm{~mm} \times 3.3 \mathrm{~mm}$ (length $\times$ width $\times$ thickness). The whole process is elucidated in Fig. 1.

\section{Characterization}

\section{Morphological characterization}

To analyze the surface morphology of composites, scanning electron microscope (SEM) was used. SEM investigation was done using SEM (Model Leo S-440), operated at accelerating voltage of $10 \mathrm{kV}$. Despite this, X-ray diffraction (XRD) analysis was performed by broker made X-ray diffractometer. The scanning range was $5^{\circ}-80^{\circ}$ along with a scanning rate of $10^{\circ} \mathrm{min}^{-1}$.

\section{Mechanical properties}

Mechanical properties for both modified and unmodified flexural and dog bone shaped composites were analyzed by using Instron universal testing machine (model 4411). Dog bone shaped tensile sample had the dimension of $15 \mathrm{~mm} \times 3 \mathrm{~mm} \times$ $3.3 \mathrm{~mm}$ (length $\times$ width $\times$ thickness) along with the total length of $60 \mathrm{~mm}$, besides flexural sample had dimension of $69.75 \mathrm{~mm} \times 12.6 \mathrm{~mm} \times 3.3 \mathrm{~mm}$ (length $\times$ width $\times$ thickness) The parameters values regarding to gauge length for tensile and flexural samples were $50 \mathrm{~mm}$ and $15 \mathrm{~mm}$, respectively, with cross head speed $1 \mathrm{~mm} \mathrm{~min}{ }^{-1}$. 

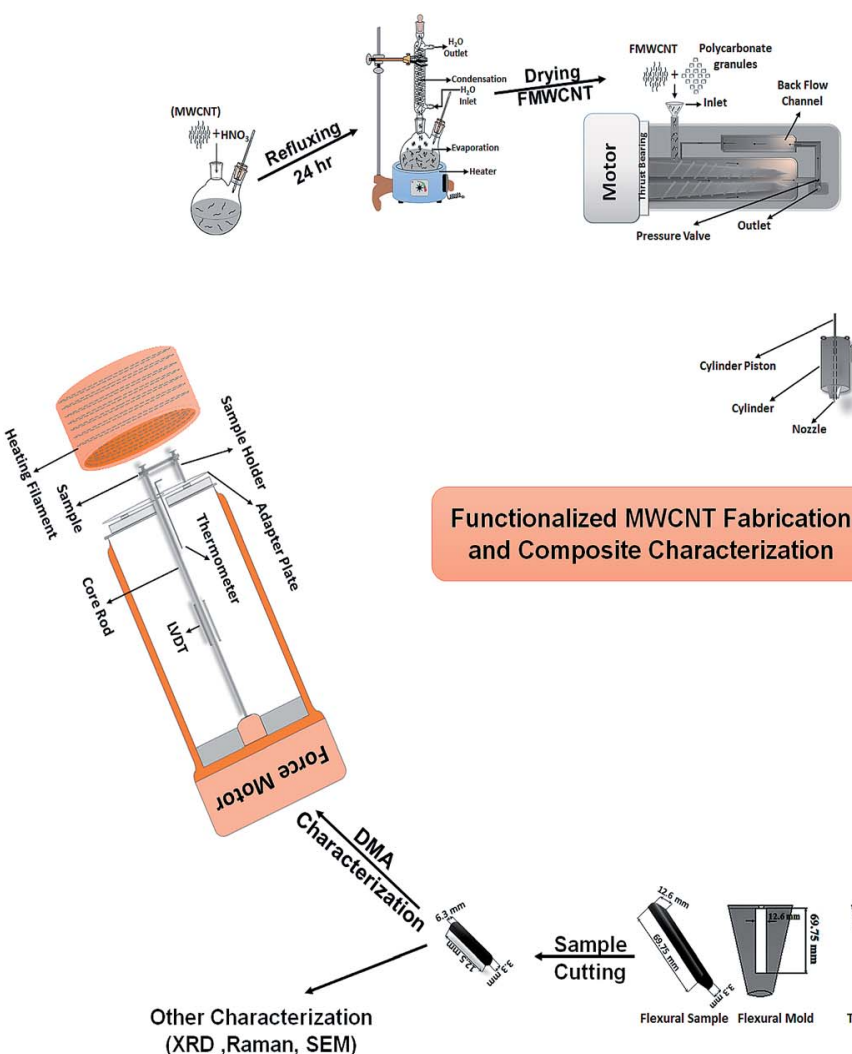

Functionalized MWCNT Fabrication and Composite Characterization (XRD ,Raman, SEM)

Fig. 1 Schematic diagram for preparation of acid functionalized MWCNT/polycarbonate composites by extrusion followed by injection molding and characterization using DMA.

\section{Dynamic mechanical thermal analysis (DMTA)}

Dynamic mechanical behavior of nanocomposites was carried out by employing dynamic mechanical analyzer (Perkin-Elmer DMA 8000 Instrument). DMTA test were performed by operating in a single cantilever clamp at a vibration frequency of 1 $\mathrm{Hz}$ from 40 to $180{ }^{\circ} \mathrm{C}$ along with scan rate of $2{ }^{\circ} \mathrm{C} \mathrm{min}^{-1}$. Samples of size $12.5 \mathrm{~mm} \times 6.3 \mathrm{~mm} \times 3.3 \mathrm{~mm}$ (length $\times$ width $\times$ thickness) were used for the test.

\section{Raman spectroscopy}

Raman spectra of composites was recorded using Renishaw in via Raman Spectrometer, UK from wavenumber range 100 $\mathrm{cm}^{-1}$ to $3000 \mathrm{~cm}^{-1}$ with excitation laser source $785 \mathrm{~nm}$ wavelength. The laser power directed was $5 \mathrm{~mW}$ for $10 \mathrm{~s}$ of exposure time.

\section{Results and discussion}

\section{Mechanical properties}

Role of both unmodified and acid modified MWCNT on the flexural and tensile properties are examined in this study. Effect of functionalization were studied only for $2 \mathrm{wt} \%$ a-MWCNT loading due to higher properties acquired for $2 \mathrm{wt} \%$ MWCNT composites by our group, described elsewhere. ${ }^{\mathbf{1 1}}$

\section{Tensile properties of MWCNT/PC and a-MWCNT/PC}

Stress-strain curve for both MWCNT/PC and a-MWCNT/PC are shown in Fig. 2. From Fig. 2(a) and (b), it is clear that elongation at break of composite material for modified and unmodified MWCNT shows only a slight variation. This enhancement in ductility behavior of a-MWNCT/PC specimen is also supported by the actually failed composite specimens (see Fig. 2(c)). After the yielding point, functionalized MWCNT composite specimens shows higher stress value over non functionalized i.e. stress value increases from $56.4 \mathrm{MPa}$ for MWCNT/PC to 57.6 MPa for a-MWCNT/PC over pure PC (48.8 MPa).

Fig. 3 shows the effect of a-MWCNT on both elastic modulus as well as tensile strength. The elastic modulus demonstrates average enhancement of $14.4 \%$ for MWCNT/PC (1574 MPa) and $14.8 \%$ for a-MWCNT/PC (1581 MPa) regarding the pure PC (1376 MPa) as shown in Fig. 3(a). The size of MWCNT also plays a crucial role in mechanical properties of the composite. Acid functionalization lead to shorten MWCNTs ${ }^{32,33}$ and to maximize stiffness of composites longer tubes are required. ${ }^{34}$

The ultimate tensile strength (UTS) of composite samples for $2 \mathrm{wt} \%$ is shown in Fig. 3(b). The average UTS value for $2 \mathrm{wt} \%$ loading shows increment $19.6 \%$ and $22 \%$ for MWCNT/PC (79.6 MPa) and a-MWCNT/PC (81.3 MPa), respectively, over pure PC (66.6 $\mathrm{MPa})$. This enhancement in tensile strength suggests that load transfer from matrix polymer to tube is improved by the functionalization of MWCNT. ${ }^{35}$ 

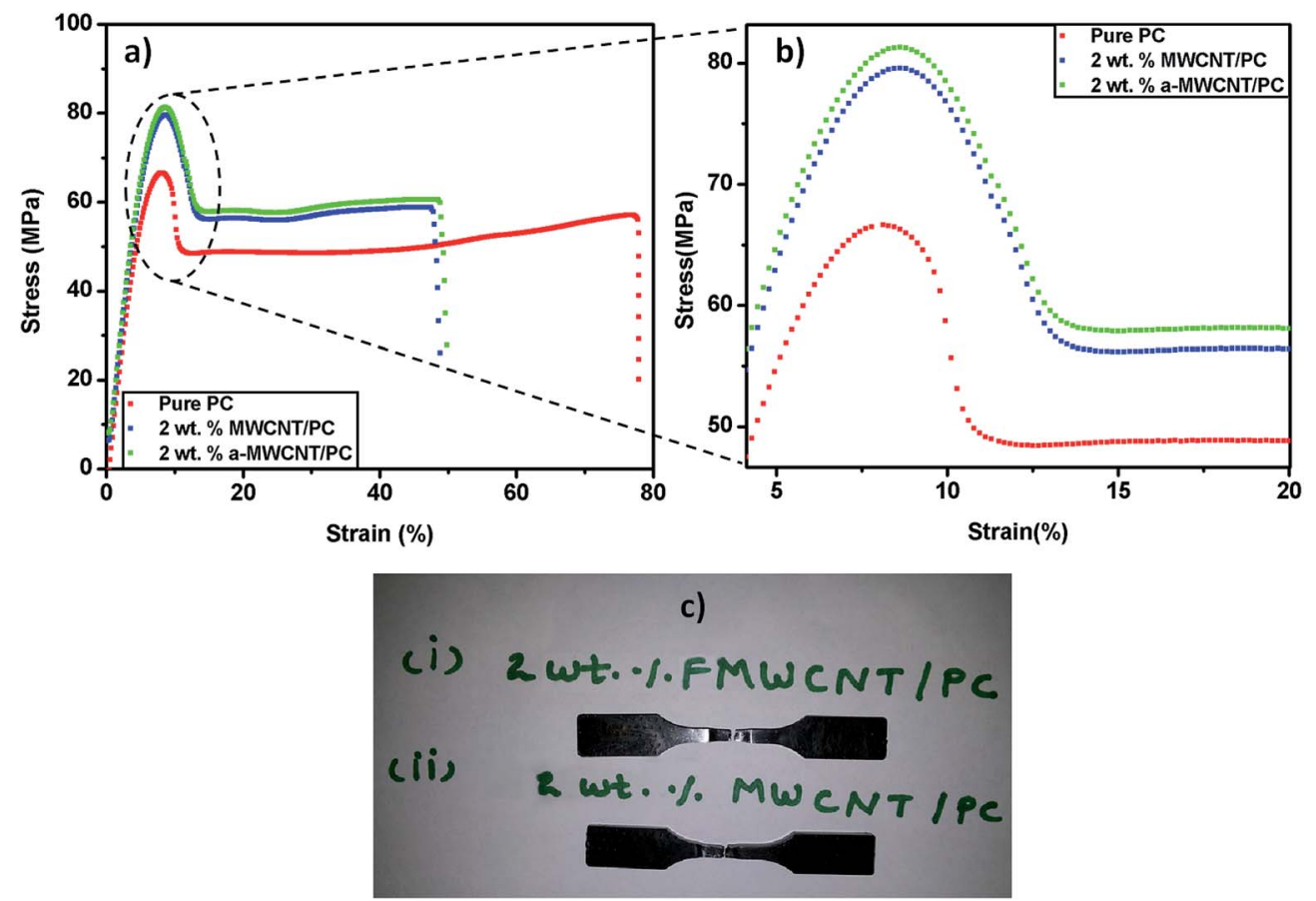

Fig. 2 Tensile stress-strain curves of: (a) MWCNT/PC and a-MWCNT/PC composites (b) zoom on stress-strain curve and (c) failed composite samples of (i) a-MWCNT and (ii) MWCNT/PC composite.

\section{Flexural properties of MWCNT/PC and a-MWCNT/PC composites}

Fig. 4 shows the effect of functionalization on flexural properties of composites. Both flexural modulus and strength increases with incorporation of a-MWCNT in contrast to as synthesized MWCNT. The improvement in flexural modulus is $11.9 \%$ and $16 \%$ for 2 wt $\%$ MWCNT (2398 MPa) and a-MWCNT (2485 MPa), respectively, with respect to pure PC (2143 MPa) (see Fig. 4(a)). On the other hand, improvement in flexural strength is $14.6 \%$ and $18.3 \%$ for both $2 \mathrm{wt} \%$ MWCNT/PC (110 MPa) and a-MWCNT/PC (113 MPa), respectively, over pure PC (96 MPa) (see Fig. 4(b)).

\section{Dynamic mechanical properties}

Dynamic mechanical analysis is a thermal analysis technique that performed to identify the properties of a material as they deforms under a periodic stress (sinusoidal stress) by measuring sinusoidal strain. The phase difference along with amplitude in the stress and strain sinusoidal waves is used to define the storage modulus and loss modulus. The storage modulus is an elastic response, related to the recoverable energy. Despite this loss modulus is a viscous response that is related to the loss of energy via internal motion. The $\tan \delta$ can be considered as a ratio of loss to storage modulus. These were calculated using formulae: ${ }^{36}$
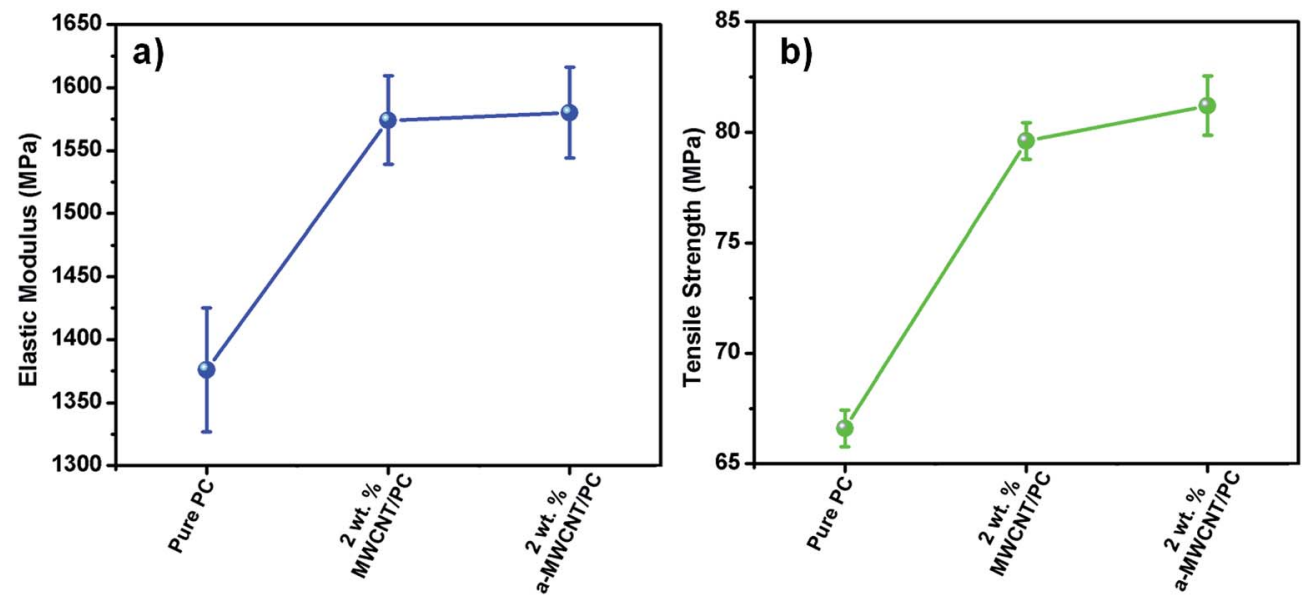

Fig. 3 Tensile properties of different composites: (a) elastic modulus and (b) tensile strength. 

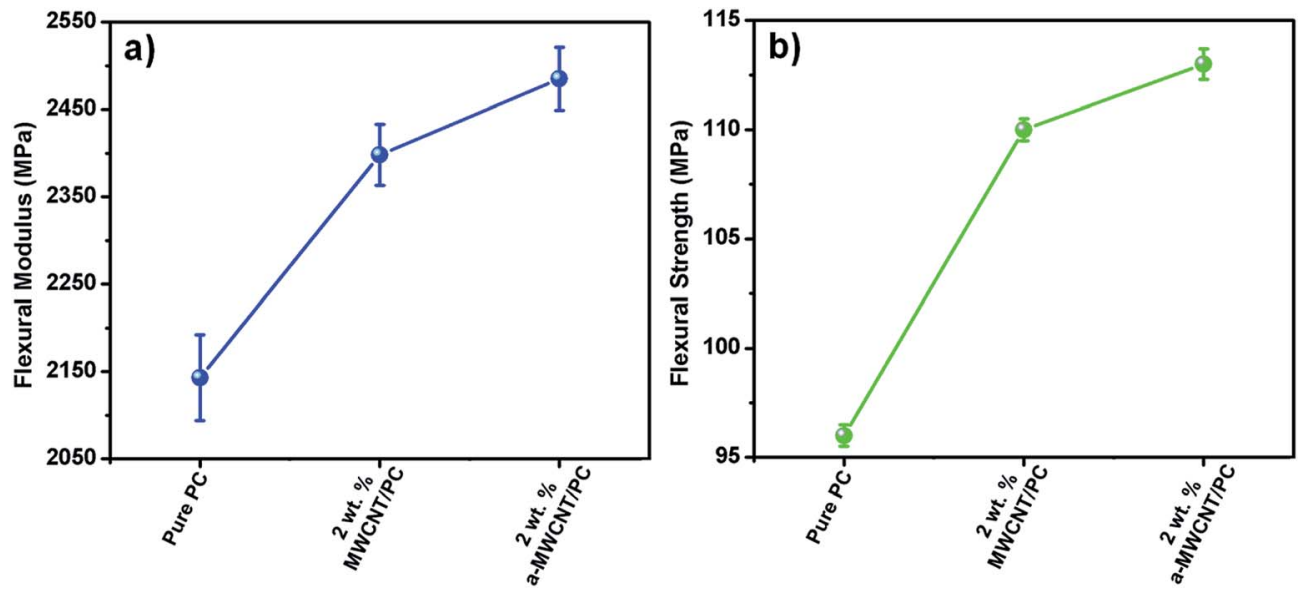

Fig. 4 Flexural properties of different composites: (a) flexural modulus, (b) flexural strength.

$$
\begin{gathered}
\text { Storage modulus }\left(E^{\prime}\right)=\rho^{\prime} / \gamma \\
\text { Loss modulus }\left(E^{\prime \prime}\right)=\rho^{\prime \prime} / \gamma \\
\tan \delta=E^{\prime \prime} / E^{\prime}
\end{gathered}
$$

where $\gamma$ is strain, $\rho^{\prime}$ and $\rho^{\prime \prime}$ are amplitude of in phase and out of phase stress component, respectively.
To understand the dynamic mechanical properties of CNT reinforced polycarbonate nanocomposites, dynamic mechanical thermal analysis was carried out. Fig. 5 shows the effect of reinforcement on storage modulus for different loading of MWCNTs. With increased loading of MWCNT, storage modulus upsurge swiftly (see Fig. 5(a)). The a-MWCNTs/PC composites have higher modulus above and below the $T_{\mathrm{g}}$ as compared to MWCNTs/PC composites. For glassy region (below $T_{\mathrm{g}}$ ), storage modulus for a-MWCNT and MWCNT/PC composites maintains
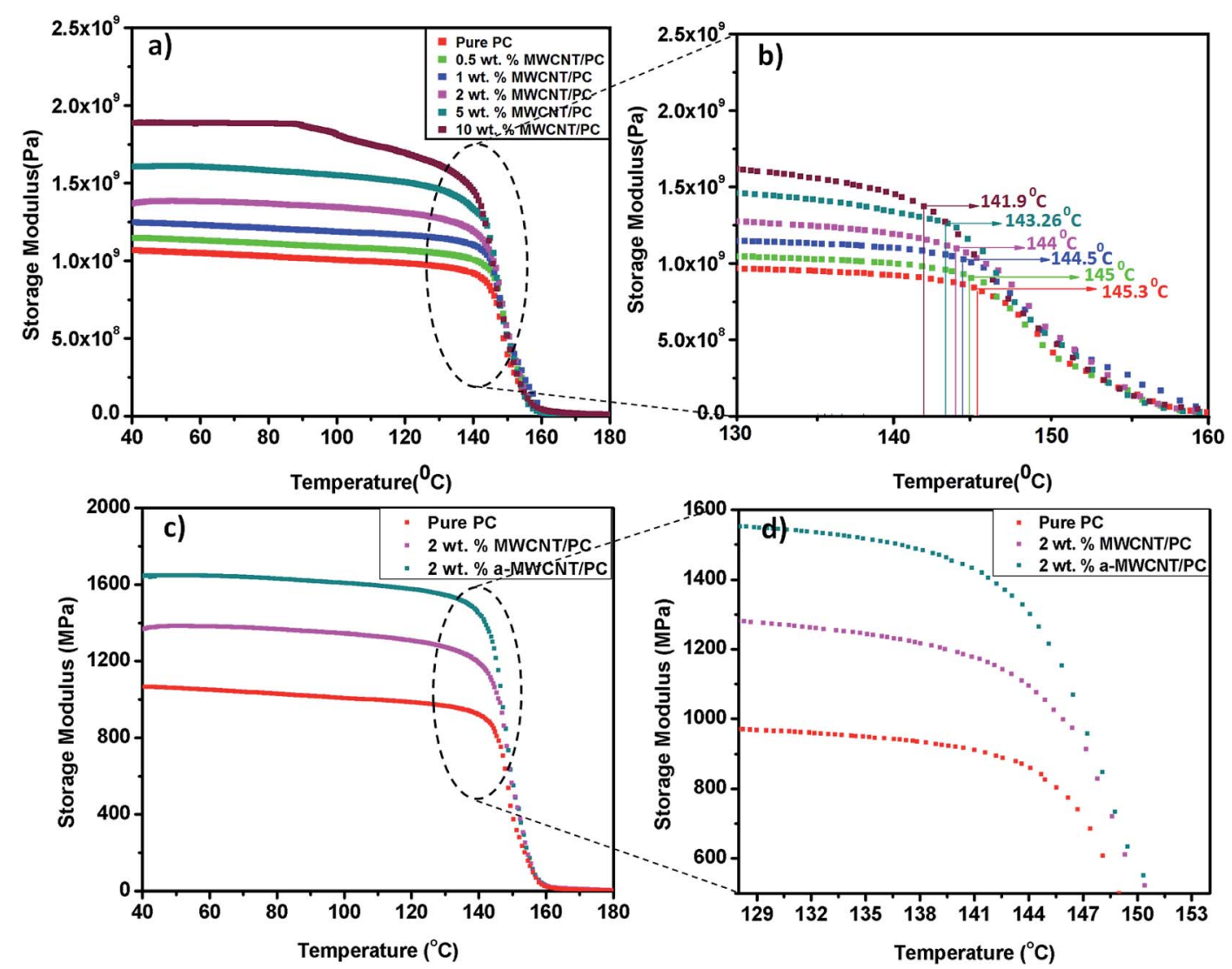

Fig. 5 Variations in storage modulus with respect to temperature (a) for different loading of MWCNT, (b) at lower range of temperature scale (zoom), (c) for modified and unmodified MWCNT and (d) at lower range of temperature scale (zoom). 

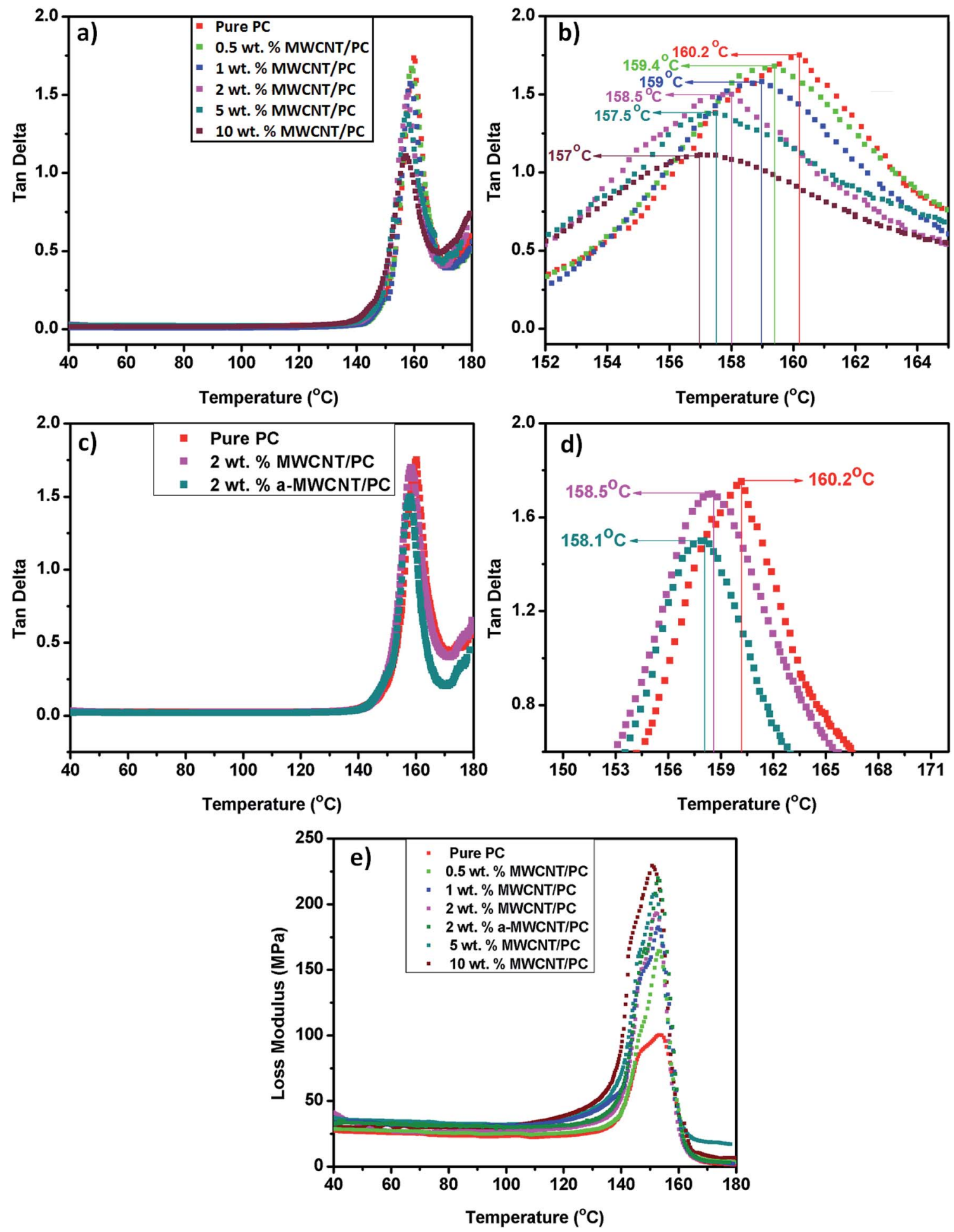

Fig. 6 Effect on dynamic mechanical properties of MWCNT/PC composites (i) tan $\delta$ : (a) for different amount of MWCNT incorporation, (b) at lower range of temperature scale (zoom), (c) for modified and unmodified $2 \mathrm{wt} \%$ MWCNT/PC composites, (d) at lower range of temperature scale (zoom) (ii) loss modulus: (e) loss modulus for different composite materials.

plateau, with no significant variance with increase in temperature. Storage modulus $\left(E^{\prime}\right)$ for $2 \mathrm{wt} \%$ a-MWCNT (1652 MPa) and MWCNT (1378 MPa) composite was 1.57 and 1.30 times greater than the pure PC $(1050 \mathrm{MPa})$ sample at $40{ }^{\circ} \mathrm{C}$, respectively (see Fig. 5(c)). On the other hand, in rubbery region (above $T_{\mathrm{g}}$ ), storage modulus rapidly decrease with increase in temperature. Storage modulus of $2 \mathrm{wt} \%$ a-MWCNT and MWCNT was $15 \mathrm{MPa}$ and $13 \mathrm{MPa}$, which was 5 and 4.33 fold more than pure PC (3 $\mathrm{MPa}$ ) at $180^{\circ} \mathrm{C}$. Increment in storage modulus is due to uniform mixing of MWCNT by applying shear stress during melt mixing 

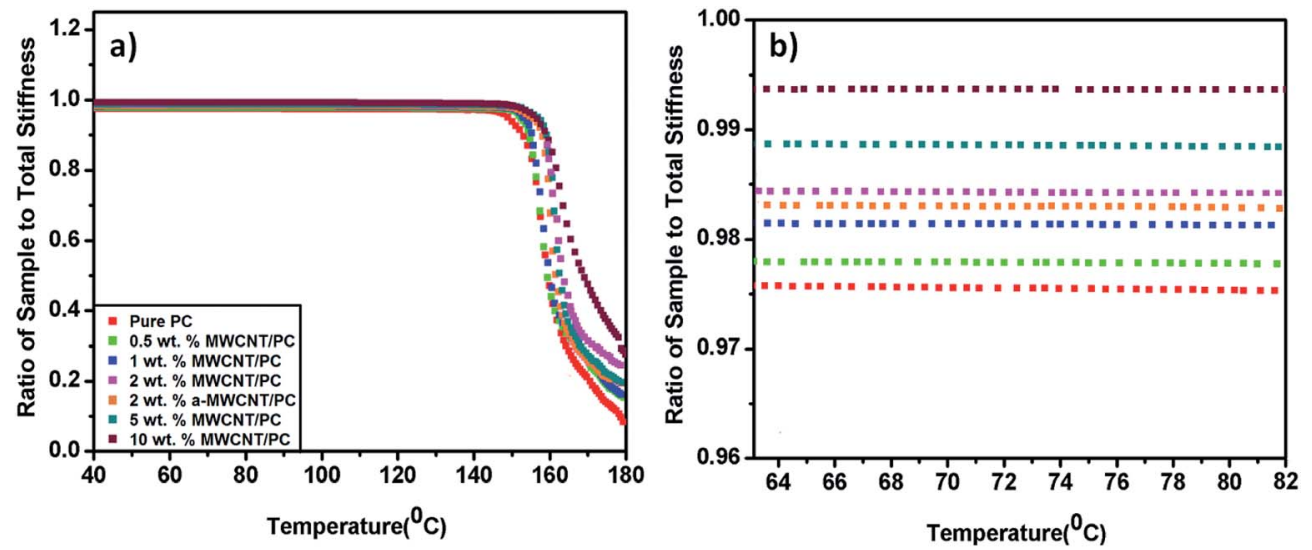

Fig. 7 Effect of temperature on stiffness (a) for different loading of modified and unmodified MWCNT and (b) at lower range of temperature scale (zoom).

that leads to the formation of MWCNT/PC chain network that act as a reinforcement below and above $T_{\mathrm{g}}$. This significant increase in modulus for a-MWCNT as comparison to MWCNT was due to strong interaction between the functional group and polymer that lead to restrictions on the mobility of polymer chain. But due to better dispersion of a-MWCNT and high amount of nano-scale confined polymer thin film between aMWCNT content lead to depression of $T_{\mathrm{g}}{ }^{23,37}$ All data regarding storage modulus are given in Table S1 (see ESI $\dagger$ ).

The $T_{\mathrm{g}}$ of PC nanocomposites resulted from both $\tan \delta$ and storage modulus $\left(E^{\prime}\right)$ showed negligible decline with respect to pure PC, almost $3{ }^{\circ} \mathrm{C}$. Few researchers also reported the reduction in $T_{\mathrm{g}}$ for MWCNT/PC composites. ${ }^{19-21}$ Fig. 5 and 6 show the $T_{\mathrm{g}}$ for varied MWCNT loading. In these measurements, point of sudden drop in $E^{\prime}$ value with temperature increment are considered as $T_{\mathrm{g}}$. The $T_{\mathrm{g}}$ calculated from $E^{\prime}$ vary from 145.3 to $142{ }^{\circ} \mathrm{C}$ for pure PC to $10 \mathrm{wt} \% \mathrm{MWCNT} / \mathrm{PC}$ composites (see Fig. 5(b)). Although $T_{\mathrm{g}}$ values calculated from $\tan \delta$ values shows similar decline but had higher temperature values than $E^{\prime}$. For pure PC, $\tan \delta$ curve shows a single peak $\left(160.2{ }^{\circ} \mathrm{C}\right)$ corresponding to the $T_{\mathrm{g}}$. Minimum value of $T_{\mathrm{g}}$ observed was $157{ }^{\circ} \mathrm{C}$ for $10 \mathrm{wt} \%$ MWCNT over the pure PC $\left(160.2^{\circ} \mathrm{C}\right)$ (see Fig. 6(b)).

The area under the $\tan \delta$ peak decreases with MWCNT loading into PC that suggested higher amount of PC confined by MWCNT and only fraction of polymer is taking part in $T_{\mathrm{g}}$. Despite of same amount of MWCNT loading, a-MWCNT/PC composites showed higher decrement in $T_{\mathrm{g}}$ with respect to pure PC (see Fig. 6(c) and (d)). Khare et al. reported higher depression in $T_{\mathrm{g}}$ for composite having highly dispersed MWCNTs as comparison to the agglomerated MWCNT. ${ }^{23}$ Functionalized MWCNT shows higher dispersion in matrix than pristine MWCNT. It leads to conclusion of presence of very small layer of matrix atoms between non-interacting nanotubes

Table 1 Glass transition temperature and storage modulus of CNT-polycarbonate composites reported recently by different authors

\begin{tabular}{|c|c|c|c|c|c|c|c|c|c|c|}
\hline \multirow[b]{3}{*}{ S. no. } & \multirow[b]{3}{*}{ Systems } & \multirow[b]{3}{*}{$T_{\mathrm{g}}\left({ }^{\circ} \mathrm{C}\right)$} & $E^{\prime}(\mathrm{MPa})$ & $E^{\prime}(\mathrm{MPa})$ & $E^{\prime}(\mathrm{MPa})$ & $E^{\prime}(\mathrm{MPa})$ & \multirow{3}{*}{$\begin{array}{l}\text { \% Increment } \\
\text { in } E^{\prime} \\
\\
40^{\circ} \mathrm{C}\end{array}$} & \multirow{3}{*}{$\begin{array}{l}\text { \% Increment } \\
\text { in } E^{\prime} \\
180^{\circ} \mathrm{C}\end{array}$} & \multirow[b]{3}{*}{ Testing method } & \multirow[b]{3}{*}{ Ref. } \\
\hline & & & \multicolumn{2}{|l|}{$180^{\circ} \mathrm{C}$} & \multicolumn{2}{|l|}{$40^{\circ} \mathrm{C}$} & & & & \\
\hline & & & Pure PC & Composite & Pure PC & Composite & & & & \\
\hline \multirow[t]{2}{*}{1} & $\begin{array}{l}\text { MWCNT } \\
(1.5,2.5,4,7,15)\end{array}$ & $156.6-146$ & & & 1.50 & & & & DMA & 20 \\
\hline & $15 \mathrm{wt} \%$ & 146 & & & & 120 & $79 \%$ & & & \\
\hline 2 & $\begin{array}{l}\text { SWCNT and } \\
\text { MWCNT }\end{array}$ & 159-154 (approx.) & 0.75 & $\begin{array}{l}3.78 \text { ( } 3 \mathrm{wt} \% \\
\text { nanocyl MWNCT) }\end{array}$ & & & $404 \%$ & $404 \%$ & DMA & 19 \\
\hline \multirow[t]{3}{*}{3} & SWCNT & & & & 1800 & & & & DMA & 21 \\
\hline & $2 \mathrm{wt} \%$ & & & & & 2418 & $33.7 \%$ & & & \\
\hline & 20 wt\% & & & & & 6215 & $245 \%$ & & & \\
\hline 4 & MWCNT & 158.5-151.5 & 1.42 & 4.43 & & & $211 \%$ & $211 \%$ & DMA & 22 \\
\hline \multirow{4}{*}{5} & Our study & $160.2-157$ & 3.00 & & 1050 & & & & DMA & \\
\hline & $2 \mathrm{wt} \%$ MWCNT & 158.5 & & 13 & & 1378 & $29.33 \%$ & $333.3 \%$ & & \\
\hline & $2 \mathrm{wt} \%$ a-MWCNT & 158.1 & & 15 & & 1652 & $57.33 \%$ & $400 \%$ & & \\
\hline & $10 \mathrm{wt} \%$ MWCNT & 157 & & 51 & & 1910 & $81.90 \%$ & $1610 \%$ & & \\
\hline
\end{tabular}



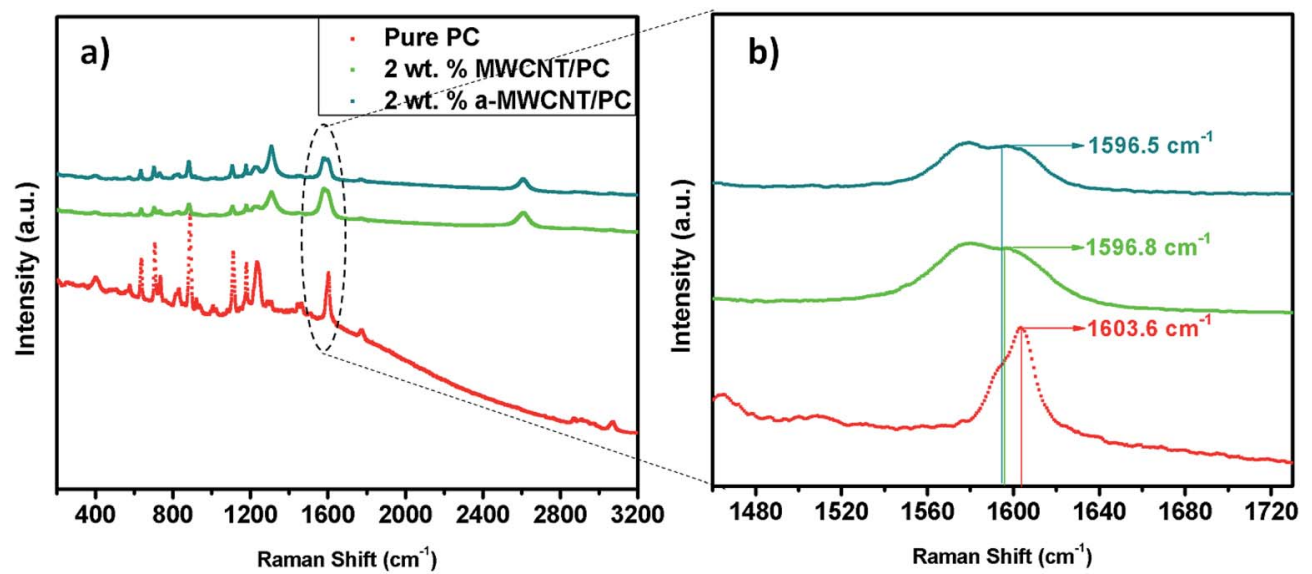

Fig. 8 Raman spectra of (a) modified and unmodified MWCNT/PC composite, (b) zoomed image of (a) for showing shifting in characteristic peak.

that act similar to polymer thin film ${ }^{37}$ causes higher $T_{\mathrm{g}}$ depression. All the parameters related to the $T_{\mathrm{g}}$ values are given in Table S2 (see ESI†). Functionalization effect on loss modulus is given in Fig. 6(e).

At present, our focus is mainly on the prior literature on the experimental studies reporting the several causes of depression in the $T_{\mathrm{g}}$. In polymer nanocomposites (PNCs), interaction of both matrix polymer and filler material create an interphase i.e. fraction of polymer that is under the hold of interfacial interaction. PNCs with weak interaction between matrix and filler material are anticipated to demonstrate depression in $T_{\mathrm{g}}$ over neat polymer because interface is comparable to the nanoscale confined polymer thin film region that enhances the free volume of thin film ${ }^{37,38}$ The magnitude of $T_{\mathrm{g}}$ is inversely proportional to the entire amounts of nanoscale confined film thickness. ${ }^{39,40} \mathrm{Few}$ researchers showed that PNCs absorb more water with increase loading under the same humid condition as compared to the neat polymer. ${ }^{41,42}$ There is increase in free volume due to high specific interfacial area where water may collect lead to decrease in $T_{\mathrm{g} .}{ }^{43}$ Some researcher showed decrease in heat capacity that suggests favorable polymer-nanotube interaction. ${ }^{44,45}$ But still due to the "correlation hole" effect in composite, enhancement in polymer mobility is seen because of the decrease in entanglement of chains near solid interface. ${ }^{46,47}$ This effect allows mobilized polymer chain (lower entanglement density) located near the immobilized polymer chain (higher entanglement density) to move easily. Due to the high shear stress applied during the melt mixing can lead to decline in molecular weight because of chain scission that ultimately cause decrease in $T_{\mathrm{g}}$ value. ${ }^{48}$ It was reported that the presence of radicals or radical promoting species on the crushed surface of MWCNT also influence the decomposition of polymer. ${ }^{49}$ Reduction of molecular weight of polymer, ${ }^{50}$ impurity incorporated during mixing and catalyst used for MWCNT synthesis ${ }^{51}$ can be proposed as a reason for decline in $T_{\mathrm{g}}$. All the parameter of $T_{\mathrm{g}}$ for MWCNT/PC composites are given in Table S2 (see ESI $\dagger$ ).

Fig. 7 shows the variation in ratio of sample to total stiffness regarding the amount of MWCNT loading. The stiffness of the composite sample enhanced swiftly with MWCNT loading.
Stiffness of composite depend upon both amount of MWCNT ${ }^{17}$ as well as length of tubes. ${ }^{34}$ The MWCNT/PC composite shows higher stiffness than a-MWCNT/PC composite on similar loading (see Fig. 7(b)).

Table 1 enlists the results on dynamic mechanical properties of CNT/PC composites reported by few authors in their studies in order for comparison with present study. As observed in the Table 1, the composites prepared in this work shows highest percentage improvement in storage modulus for both glassy and rubbery region as well as lowest depression in overall $T_{g}$ from pure to $10 \mathrm{wt} \% \mathrm{MWCNT} / \mathrm{PC}\left(3.2{ }^{\circ} \mathrm{C}\right)$ compared to other studies provided in literature. Additionally, the functionalization effect on dynamic mechanical properties of PC composite is uniquely studied. The a-MWCNT composite shows higher improvement in storage modulus as compared to as synthesized MWCNT because of the better interaction between the matrix polymer and a-MWCNT. This perception of improvement in interaction between matrix and a-MWCNT due to
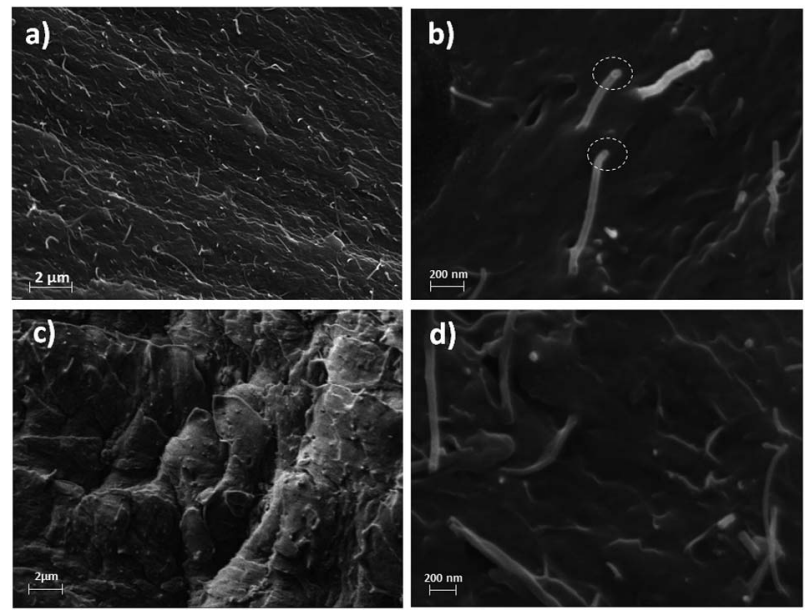

Fig. 9 SEM micrograph of (a) 2 wt\% MWCNT/PC composite, (b) magnified micrograph shows pullout MWCNTs in MWCNT/PC composite, (c) 2 wt\% a-MWCNT/PC composite and (d) magnified micrograph shows embedded nanotubes. 

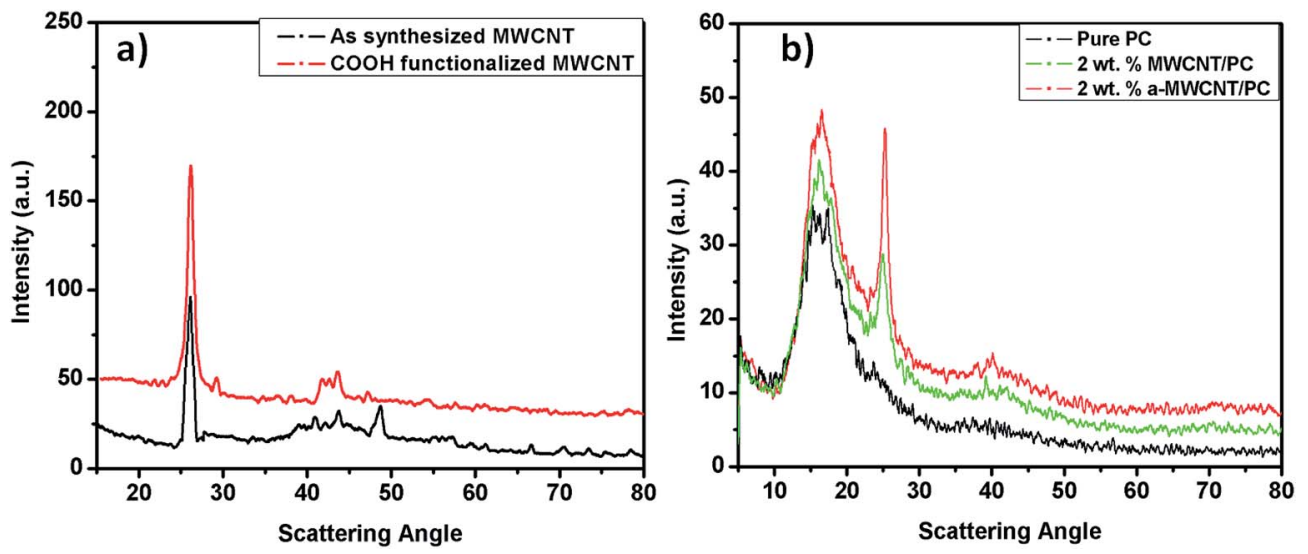

Fig. 10 XRD pattern of modified and unmodified (a) MWCNT and (b) reinforced polycarbonate composite.

functionalization is also confirmed by Raman spectroscopy analysis and SEM micrographs.

Raman spectroscopy analysis of composites was carried out in order to investigate the interaction of both MWCNT and aMWCNT with the PC matrix. Fig. 8 shows the Raman spectrum of PC composites. Incorporation of CNT lead to duplet formation in the characteristic peak of PC situated at 1603.6 $\mathrm{cm}^{-1}$. For a-MWCNT/PC composites, shifting in the peak situated at higher wavenumber is slightly higher compared to MWCNT/PC composites (see Fig. 8(a) and (b)). This shifting reveal that a-MWCNTs have higher interaction than MWCNT because shifting shows the degree of interaction between PC and CNT. ${ }^{11,52}$ Fig. 8(b) shows the shift in characteristic peaks of composites within higher magnification.

SEM was carried out to investigate the effect of functionalization on surface morphology of composite samples. SEM micrograph of composite sample is shown in Fig. 9. The SEM and TEM studies of as produced MWCNTs and a-MWCNTs were studied in detail previously ${ }^{30}$ where defects sites were clearly seen in the functionalized CNTs and metallic impurities were also been removed after functionalization. As for the unmodified MWCNT shown in Fig. 9(a) and (b), the fractured surface of composite samples displays higher amount of pullout MWCNT, which indicate weak interfacial bonding between PC matrix and MWCNTs. In functionalized MWCNT composite samples, nanotube ends are embedded into the matrix polymer and forming arches like shapes (see Fig. 9(d)). These nanotubes appear as dots on the broken surface. From SEM micrographs it can be observed that a-MWCNT shows better wetting with the polymer host as compared to the unmodified MWCNT. These results shows resemblance with increment in both elastic modulus and storage modulus obtained for a-MWCNT/PC composites over MWCNT/PC composites.

Fig. 10(a) shows the XRD of as produced MWCNTs and aMWCNTs. XRD peaks were identified as 26 (C(002)), 41.5 (C(100)), 42.8 (C(101)), $44.4(\mathrm{Fe}(011)), 78(\mathrm{C}(110))$ for as produced MWCNTs and 26 (C(002)), 42.8 (C(100)), $43.6(\mathrm{C}(101))$, $44.7(\mathrm{Fe}(011)), 78(\mathrm{C}(110))$ for a-MWCNT (see ESI, Table S3†). Fig. 10(b) shows the X-ray diffraction pattern of pure PC and its composites. For pure PC, XRD pattern shows a broad peak at
$2 \theta=16.2^{\circ}$ associated with the amorphous PC and the position of the peak remain unchanged after introduction of MWCNT and a-MWCNT. Incorporation of MWCNT and a-MWCNT bring about a new peak at $2 \theta=26^{\circ}$ and $42.2^{\circ}$ that shows (002) and (100) planes of carbon atom along with the interlayer spacing among the graphitic layers of MWCNT. ${ }^{53-55}$ Few studies revealed, a-MWCNT have sharp peak than same amount of MWCNT loading without drastic change in position of the characteristic peaks, shown in Fig. 10(a). This suggests that after functionalization MWCNT retain their original structure. From Fig. 10, it is clear that peak sharpness for composites increase with higher MWCNT and a-MWCNT loading that result in more regular structure (crystallinity) ${ }^{56,57}$ This is also consistent with the thermal analysis of composites. ${ }^{20}$

\section{Conclusion}

Acid functionalized MWCNT/PC nanocomposites exhibit higher flexural and tensile properties and storage modulus as compared to the non-functionalized MWCNT/PC nanocomposites. Higher loading of MWCNT leads to enhancement in storage modulus over whole temperature scale. For $2 \mathrm{wt} \%$ MWCNT and a-MWCNT/PC composites, the improvement in storage modulus for glassy region is $29.3 \%$ and $57.3 \%$, respectively, while in rubbery region it enhances up to $333.3 \%$ and $400 \%$, respectively, over pure PC. Raman spectroscopy confirms that a-MWCNT shows higher interaction to matrix polymer as comparison to as synthesized MWCNT. Improvement in interaction between a-MWCNT and PC matrix is also verified using SEM. MWCNT/PC composites show depression in $T_{\mathrm{g}}$ with increased amount of CNT but this decline is much lesser then previously reported studies i.e. $10 \mathrm{wt} \% \mathrm{MWCNT} / \mathrm{PC}\left(157^{\circ} \mathrm{C}\right)$ composite shows only $3.2{ }^{\circ} \mathrm{C}$ depression in $T_{\mathrm{g}}$ in contrast to pure PC $\left(160.2^{\circ} \mathrm{C}\right)$. Depression in $T_{\mathrm{g}}$ is due to increase in free surface of polymer that is in nanoscale confinement.

\section{Acknowledgements}

The authors wish to express their gratitude to Director CSIRNational Physics Laboratory, for his keen interest in this 
work. Authors are thankful to Mr Jay Tawale for SEM measurement, Mrs Shaveta Sharma for carrying out mechanical properties and Dr N. Viajayan for XRD measurement of the samples. The studies were carried out under the CSIR network project (PSC0109).

\section{References}

1 S. Iijima, Nature, 1991, 354, 56-58.

2 B. P. Grady, Carbon nanotube-polymer composites: manufacture, properties, and applications, John Wiley \& Sons, 2011.

3 C.-M. Chang and Y.-L. Liu, ACS Appl. Mater. Interfaces, 2011, 3, 2204-2208.

4 R. Xu and X. Xu, RSC Adv., 2014, 4, 42226-42233.

5 S. Pande, A. Chaudhary, D. Patel, B. P. Singh and R. B. Mathur, RSC Adv., 2014, 4, 13839-13849.

6 E. Roumeli, A. Avgeropoulos, E. Pavlidou, G. Vourlias, T. Kyratsi, D. Bikiaris and K. Chrissafis, RSC Adv., 2014, 4, 45522-45534.

7 Y. Sohn, D. Kim, S. Lee, M. Yin, J. Y. Song, W. Hwang, S. Park, H. Kim, Y. Ko and I. Han, J. Mater. Chem. A, 2014, 2, 1146511471.

8 P. Jindal, S. Pande, P. Sharma, V. Mangla, A. Chaudhury, D. Patel, B. P. Singh, R. B. Mathur and M. Goyal, Composites, Part B, 2013, 45, 417-422.

9 S. Pande, B. P. Singh and R. B. Mathur, Polymer Nanotube Nanocomposites, John Wiley \& Sons, Inc., 2014, pp. 333364, DOI: 10.1002/9781118945964.ch9.

10 K. H. Kim and W. H. Jo, Carbon, 2009, 47, 1126-1134.

11 A. SingháBabal, B. PratapáSingh and V. NandáSingh, RSC Adv., 2014, 4, 64649-64658.

12 J. Yan and Y. G. Jeong, Appl. Phys. Lett., 2014, 105, 051907.

13 R. Allen, L. Pan, G. G. Fuller and Z. Bao, ACS Appl. Mater. Interfaces, 2014, 6, 9966-9974.

14 B. P. Singh, K. Saini, V. Choudhary, S. Teotia, S. Pande, P. Saini and R. B. Mathur, J. Nanopart. Res., 2014, 16, 1-11.

15 S. K. Kumar and R. Krishnamoorti, Annu. Rev. Chem. Biomol. Eng., 2010, 1, 37-58.

16 B. P. Singh, V. Choudhary, S. Teotia, T. K. Gupta, V. N. Singh, S. R. Dhakate and R. B. Mathur, Adv. Mater. Lett., 2015, 6, 104-113.

17 L. Schadler, S. Giannaris and P. Ajayan, Appl. Phys. Lett., 1998, 73, 3842-3844.

18 B. P. Singh, V. Choudhary, P. Saini, S. Pande, V. N. Singh and R. B. Mathur, J. Nanopart. Res., 2013, 15, 1-12.

19 F. Y. Castillo, R. Socher, B. Krause, R. Headrick, B. P. Grady, R. Prada-Silvy and P. Pötschke, Polymer, 2011, 52, 3835-3845.

20 Y. Sung, C. Kum, H. Lee, N. Byon, H. Yoon and W. Kim, Polymer, 2005, 46, 5656-5661.

21 S. Wang, Z. Liang, G. Pham, Y.-B. Park, B. Wang, C. Zhang, L. Kramer and P. Funchess, Nanotechnology, 2007, 18, 095708.

22 J. Guo, Y. Liu, R. Prada-Silvy, Y. Tan, S. Azad, B. Krause, P. Pötschke and B. P. Grady, J. Polym. Sci., Part B: Polym. Phys., 2014, 52, 73-83.
23 K. S. Khare and R. Khare, J. Phys. Chem. B, 2013, 117, 74447454.

24 J. Fidelus, E. Wiesel, F. Gojny, K. Schulte and H. Wagner, Composites, Part A, 2005, 36, 1555-1561.

25 S. Boncel, K. K. Koziol, K. Z. Walczak, A. H. Windle and M. S. Shaffer, Mater. Lett., 2011, 65, 2299-2303.

26 L. Guadagno, B. De Vivo, A. Di Bartolomeo, P. Lamberti, A. Sorrentino, V. Tucci, L. Vertuccio and V. Vittoria, Carbon, 2011, 49, 1919-1930.

27 I. T. Amr, A. Al-Amer, M. Al-Harthi, S. A. Girei, R. Sougrat and M. A. Atieh, Composites, Part B, 2011, 42, 1554-1561.

28 R. B. Mathur, S. Chatterjee and B. P. Singh, Compos. Sci. Technol., 2008, 68, 1608-1615.

29 T. K. Gupta, B. P. Singh, R. B. Mathur and S. R. Dhakate, Nanoscale, 2014, 6, 842-851.

30 T. K. Gupta, B. P. Singh, S. R. Dhakate, V. N. Singh and R. B. Mathur, J. Mater. Chem. A, 2013, 1, 9138-9149.

31 B. P. Singh, D. Singh, R. B. Mathur and T. L. Dhami, Nanoscale Res. Lett., 2008, 3, 444-453.

32 S. Frankland, A. Caglar, D. Brenner and M. Griebel, J. Phys. Chem. B, 2002, 106, 3046-3048.

33 Z. Zhang, B. Liu, Y. Chen, H. Jiang, K. Hwang and Y. Huang, Nanotechnology, 2008, 19, 395702.

34 J. N. Coleman, U. Khan, W. J. Blau and Y. K. Gun'ko, Carbon, 2006, 44, 1624-1652.

35 A. Oliver, J. Bult, Q. V. Le, A. L. Mbaruku and J. Schwartz, Nanotechnology, 2008, 19, 505702.

36 Y. M. Boiko, W. Brostow, A. Y. Goldman and A. Ramamurthy, Polymer, 1995, 36, 1383-1392.

37 K. W. Putz, M. J. Palmeri, R. B. Cohn, R. Andrews and L. C. Brinson, Macromolecules, 2008, 41, 6752-6756.

38 D. Ciprari, K. Jacob and R. Tannenbaum, Macromolecules, 2006, 39, 6565-6573.

39 J. Forrest, K. Dalnoki-Veress and J. Dutcher, Phys. Rev. E, 1997, 56, 5705.

40 J. A. Forrest, K. Dalnoki-Veress, J. R. Stevens and J. R. Dutcher, Phys. Rev. Lett., 1996, 77, 2002-2005.

41 S. S. Sternstein and A.-J. Zhu, Macromolecules, 2002, 35, 7262-7273.

42 J. Nelson and Y. Hu, J. Phys. D: Appl. Phys., 2005, 38, 213.

43 C. Zou, M. Fu, J. C. Fothergill and S. W. Rowe, IEEE Conference, 2006, 321-324.

44 A. Sargsyan, A. Tonoyan, S. Davtyan and C. Schick, Eur. Polym. J., 2007, 43, 3113-3127.

45 R. D. Priestley, C. J. Ellison, L. J. Broadbelt and J. M. Torkelson, Science, 2005, 309, 456-459.

46 Y. Li, D. Wei, C. C. Han and Q. Liao, J. Chem. Phys., 2007, 126, 204907.

47 M. Mukhopadhyay, X. Jiao, L. Lurio, Z. Jiang, J. Stark, M. Sprung, S. Narayanan, A. Sandy and S. Sinha, Phys. Rev. Lett., 2008, 101, 115501.

48 P. Pötschke, A. R. Bhattacharyya, A. Janke and H. Goering, Compos. Interfaces, 2003, 10, 389-404.

49 S. Peeterbroeck, F. Laoutid, B. Swoboda, J.-M. Lopez-Cuesta, N. Moreau, J. B. Nagy, M. Alexandre and P. Dubois, Macromol. Rapid Commun., 2007, 28, 260-264. 
50 P. Pötschke, A. R. Bhattacharyya and A. Janke, Carbon, 2004, 42, 965-969.

51 B. B. Marosfoi, G. J. Marosi, A. Szep, P. Anna, S. Keszei, B. J. Nagy, H. Martvona and I. E. Sajo, Polym. Adv. Technol., 2006, 17, 255-262.

52 L. Bokobza and J. Zhang, eXPRESS Polym. Lett., 2012, 6, 601608.

53 G.-W. Lee, J. Kim, J. Yoon, J.-S. Bae, B. C. Shin, I. S. Kim, W. Oh and M. Ree, Thin Solid Films, 2008, 516, 5781-5784.
54 F. Wu and H. Cheng, J. Phys. D: Appl. Phys., 2005, 38, 4302. 55 Y. Cheng, W. Li, X. Fan, J. Liu, W. Xu and C. Yan, Electrochim. Acta, 2013, 111, 635-641.

56 P. Kar and A. Choudhury, Sens. Actuators, B, 2013, 183, 2533.

57 S. Pisal, N. Harale, T. Bhat, H. Deshmukh and P. Patil, IOSRJ. Appl. Chem., 2014, 7, 49-52. 